\title{
A Qualitative Study on The Function of Information and Communication Technology Utilization in Teaching Students with Intellectual Disabilities: Implications for Techniques of Teaching/Job Coaching
}

\author{
Kazuaki Maebara ${ }^{1, *}$, Asuka Yamaguchi $^{2}$, Toru Suzuki $^{1}$ and Aya Imai ${ }^{3}$ \\ ${ }^{1}$ Faculty of Education and Human Studies, Akita University, Akita, Japan \\ ${ }^{2}$ Faculty of Human Development, Takamatsu University, Kagawa, Japan \\ ${ }^{3}$ The School for Special Needs, Department of Education and Human, Akita University, Akita, Japan
}

\begin{abstract}
Background: Recently, the use of Information and Communication Technology (ICT) in education has been promoted in Japan. However, teachers do not yet fully understand using ICT for persons with intellectual disabilities.

Objective: This study clarifies the support functions of ICT as perceived by teachers involved in special needs education (support for students with intellectual disabilities).

Methods: We conducted in-depth interviews with five teachers involved in special-needs education. We qualitatively analyzed the interview data obtained using content analysis.

Results: From the interviews, 53 ICT-utilization episodes were obtained. These episodes were categorized into 13 categories of utilization and seven aspects of support: understanding, communication, behavior, meta-cognition, environment, memory, and opportunities.

Conclusion: ICT is a beneficial tool to compensate for intellectual disabilities and help students with intellectual disabilities learn better. We believe that teachers can better assist students with intellectual disabilities by successfully matching individual needs with the ICT features. The results obtained in this study will be helpful while considering support for persons with intellectual disabilities, not only in education but also in vocational training, employment support, and telework support for persons with intellectual disabilities.
\end{abstract}

Keywords: Intellectual disability, special needs education, assistive technology, information and communication technology, teleworking.

\section{INTRODUCTION}

Individuals with intellectual disabilities are characterized by intellectual functioning and adaptive behavior limitations, represented by a lack of conceptual, social, and practical adaptive skills [1]. As a result of this incapacity, persons with intellectual disabilities encounter a wide range of barriers in various social situations. Abbott and McConkey reported four types of barriers perceived by persons with intellectual disabilities: lack of necessary knowledge and skills, the role of support staff and service managers, location of the house, and community factors such as lack of amenities and attitudes [2]. Lippold and Burns, in a comparison of the social networks of persons with intellectual disabilities and persons with physical disabilities, noted that persons with intellectual disabilities are characterized by more limited social networks and especially fewer networks with normal persons [3]. From their interviews

*Address correspondence to this author at the Akita University, 1-1, TegataGakuen Machi, Akita, 010-8502, Japan; Tel: +8118-889-2548; Fax: +8118-8892548; E-mail: maebara-kazuaki@ed.akita-u.ac.jp with persons with intellectual disabilities, Patterson and Pegg reported that leisure activities have a significant positive impact on community inclusion and noted the need to provide leisure activities for persons with intellectual disabilities [4].

It is important to understand that the barriers encountered by persons with intellectual disabilities do not arise because of their individual intellectual disabilities but rather because of their interaction with their environment via social and interpersonal relationships. In this sense, there is a need for intervention in the environment surrounding persons with intellectual disabilities. Martorell et al. reported from a survey of persons with intellectual disabilities working in protective employment that the transition to employment for persons with intellectual disabilities requires not only personal effort but social support as well [5]. This type of intervention on the part of society will help persons with intellectual disabilities become more independent. In fact, it is important to help persons with intellectual disabilities gain independence for their social participation and adaptive behavior. However, it is necessary to consider their environment 
before determining that they lack the capacity for independence. Among the various possible considerations, the use of Information and Communication Technology (ICT) equipment can be considered a viable and effective technological support for persons with intellectual disabilities [7].

In recent years, Japan's Ministry of Education, Culture, Sports, Science, and Technology (MEXT) has been promoting the "GIGA School Initiative," an educational program that uses ICT devices to maximize children's abilities [8]. In this "GIGA School Initiative." the children's ability to use information is as fundamental as developing their language skills, which is why the enhancement of ICT-based classes is being promoted in schools. As a result, many schools are now equipped with ICT devices (such as tablets) made available for use in the classroom. This is also being promoted in special needs education in Japan, where ICT devices have been used as an effective tool to supplement children's cognitive disabilities [9]. Special education also plays a very important role in supporting the transition of students with intellectual disabilities to the workplace. Therefore, educating students in the use of ICT is beneficial for promoting their future independence and enabling them to leverage the reasonable accommodations provided in the workplace when they are hired as employees in the future.

Even though ICT devices are useful tools for students with intellectual disabilities, they are still not fully utilized in the education and support of these students in Japan. There are many practical reports on ICT use in special support schools for students with intellectual disabilities [10-15]. However, most teachers are not sufficiently aware of the usefulness of ICT applications for persons with intellectual disabilities. Eda reported from a survey that while teachers are aware of the need to incorporate ICT, they still find it difficult to use ICT [16]. Therefore, Japanese teachers still find it challenging to adopt ICT in the education and support of students with intellectual disabilities. One of the reasons behind this difficulty is that teachers still do not fully understand the specific strategies for using ICT devices in the education of students with intellectual disabilities. For teachers to confidently use ICT devices, it is necessary to share more functions for the use of such ICT devices. Therefore, this study aims to clarify the functions of ICT devices in special needs education, especially for students with intellectual disabilities in vocational education classes.

\section{METHODS}

\section{Participants}

In this study, the participants were teachers involved in special needs education. Every day, teachers involved in special needs education provide specialized education for students with intellectual disabilities. One of those classes is a vocational class where the teacher provides training and guidance on vocations. Therefore, we judged that a teacher involved in special needs education would be an appropriate participant for this study. First, we asked one teacher who was using ICT in special needs education to cooperate in the survey, and then we asked the teacher to introduce a suitable research participant for the study. The research participants were five teachers working at special needs schools listed in Table 1. Participants' years of teaching experience in special schools ranged from 12 to 23 years and in the high school sector from 6 to 12 years.

\section{Procedure}

We conducted a single 60-minute interview survey with five participating teachers. In this research, we conducted in-depth interviews using the interview items listed in Table 2.

The interviews were recorded using an Integrated Circuit recorder. The data was recorded verbatim and used as raw data for the analysis. The average number

Table 1: Description of the Research Participants

\begin{tabular}{|c|c|c|c|c|}
\hline No. & Participants & Gender & $\begin{array}{c}\text { Years of teaching } \\
\text { experience }\end{array}$ & $\begin{array}{c}\text { Years of teaching experience in the high } \\
\text { school sector }\end{array}$ \\
\hline \hline 1 & A & Male & 15 & 10 \\
\hline 2 & B & Male & 23 & 7 \\
\hline 3 & C & Male & 17 & 6 \\
\hline 4 & D & Male & 19 & 12 \\
\hline 5 & E & Female & 12 & \\
\hline
\end{tabular}


Table 2: Interview Items

\begin{tabular}{|l|}
\hline Items \\
\hline \hline Talk about your thoughts on teleworking after graduation. \\
\hline - Please, tell us about your experience of using ICT in vocational education. \\
\hline - Please, tell us your opinion about the effects of using ICT in vocational education. \\
\hline - Please, tell us what you think are the issues facing the use of ICT. \\
\hline - Please, tell us about your experience of using ICT effectively in the classroom. \\
\hline - Please, tell us what kind of support you think is needed for future telework by persons with intellectual disabilities. \\
\hline
\end{tabular}

of characters in the recorded raw data was 8073 , with a standard deviation of 1941.74 characters.

\section{Methods of Analysis}

The data obtained were analyzed qualitatively using content analysis [17]. The specific procedure of the analysis was as follows: First, based on the research purpose, the analytical focus of this study was determined to be the specific use of ICT in vocational education for students with intellectual disabilities. Next, the meaning of the episodic data and their similarities and differences in the contexts were continuously compared with the coauthors. From time to time, discussions were held with co-researchers and others who had practical experience as teachers. Finally, the episodes were divided into categories, and the categories were organized as support perspectives for persons with intellectual disabilities.

\section{Ethical Considerations}

The aims and objectives of the study were stated prior to the participant who provided their consent to participate in the study. This study was approved by the Ethical Review Committee for Research Involving Human Subjects at Akita University, No. 3-6, dated June 7, 2021.

\section{RESULTS}

The qualitative analysis yielded 53 episodes in which ICT was used in vocational education for students with intellectual disabilities. The teacher's educational episodes on ICT use could be classified into 13 subcategories based on their functions. These subcategories can be further organized into seven categories as their supporting perspectives, as shown in Table 3.

\section{Category: Support Perspective "Understanding"}

In this, the teacher used ICT to supplement the understanding of work instructions and teaching content for students with intellectual disabilities. Regarding the subcategory, the teacher used ICT to help enhance understanding of intellectual disabilities, such as "coordination and point clarification," "repetition," "visual aids," "comparison," and "inhibiting environmental stimuli." Based on this perspective of support, these subcategories were grouped as categories of understanding. The details of each subcategory are as follows:

\section{Coordination and Point Clarification}

This utilization method encourages students to understand the instructions by writing key points in letters and notes on the video and photos taken. As shown in Figure 1, after taking a picture of the space to be cleaned, work instructions were given by marking the cleaning area and direction on the picture with a pen and highlighting the points of interest in the picture with circles.

\section{Repetition}

This utilization method allows students to check work instructions repeatedly using a recorded video of the work instructions. For example, the work instructions were recorded in advance as a video. When the students had any questions, they were instructed to review the video of the work instructions.

\section{Visual Aids}

This is being utilized by using videos and photos to provide work instructions to students. For example, work instructions were created using photos, and the students were asked to check the photos regarding the work instructions for each step of the process. The actual products were also shared on the screen to help them understand the concepts to be learned.

\section{Comparison}

This utilization method involves using videos and photos to convey the completed state of a job or the optimal work behavior and having the students learn it 
Table 3: Information and Communication Technology (ICT) Utilization Methods and Support Perspectives

\begin{tabular}{|c|c|c|c|c|}
\hline $\begin{array}{l}\text { Category: Support } \\
\text { perspective }\end{array}$ & $\begin{array}{l}\text { Number of } \\
\text { episodes }\end{array}$ & $\begin{array}{l}\text { Subcategories: } \\
\text { Utilization methods }\end{array}$ & $\begin{array}{l}\text { Number of } \\
\text { episodes }\end{array}$ & Examples of episodes \\
\hline \multirow[t]{5}{*}{ Understanding } & \multirow[t]{5}{*}{17} & $\begin{array}{l}\text { Coordination and point } \\
\text { clarification }\end{array}$ & 4 & $\begin{array}{l}\text { Students can better understand the instructions by } \\
\text { writing notes on the worksheet or instructions they want } \\
\text { to emphasize on the recorded videos or photos. }\end{array}$ \\
\hline & & Repetition & 5 & $\begin{array}{l}\text { By recording the work instructions, students can better } \\
\text { understand the repeated work instructions. }\end{array}$ \\
\hline & & Visual aids & 5 & $\begin{array}{l}\text { Using videos and photos in instructions can help } \\
\text { students understand the instructions better. }\end{array}$ \\
\hline & & Comparison & 2 & $\begin{array}{l}\text { Students can better understand the work objectives by } \\
\text { comparing them with the finished samples. }\end{array}$ \\
\hline & & $\begin{array}{l}\text { Inhibiting environmental } \\
\text { stimuli }\end{array}$ & 1 & $\begin{array}{l}\text { Online, individualized learning spaces with less } \\
\text { distracting environmental stimuli allow students to } \\
\text { understand the teacher's instructions better. }\end{array}$ \\
\hline \multirow[t]{2}{*}{ Communication } & \multirow[t]{2}{*}{9} & Interaction & 6 & $\begin{array}{l}\text { By interacting extensively with others besides the } \\
\text { teacher, students have more opportunities to } \\
\text { communicate. }\end{array}$ \\
\hline & & Sharing with others & 3 & $\begin{array}{l}\text { By using presentation apps, students can share and } \\
\text { communicate with other students what they have learned } \\
\text { more easily. }\end{array}$ \\
\hline \multirow[t]{2}{*}{ Behavior } & \multirow[t]{2}{*}{6} & Writing & 3 & $\begin{array}{l}\text { Students will be able to enter and rewrite sentences, } \\
\text { making note-taking easier for them. }\end{array}$ \\
\hline & & $\begin{array}{l}\text { Supporting positive } \\
\text { behavior }\end{array}$ & 3 & $\begin{array}{l}\text { Allow students to search independently based on their } \\
\text { own interests and concerns. }\end{array}$ \\
\hline Meta-cognition & 9 & Feedback & 9 & $\begin{array}{l}\text { Students can record their work activities and use the } \\
\text { recorded video to check their own activities. }\end{array}$ \\
\hline Environment & 5 & $\begin{array}{l}\text { Environmental } \\
\text { supplementation }\end{array}$ & 5 & $\begin{array}{l}\text { A variety of applications and software can be used to } \\
\text { make up for the lack of educational materials. }\end{array}$ \\
\hline Memory & 4 & History reference & 4 & $\begin{array}{l}\text { By recording and storing data on what they have } \\
\text { learned, students can reflect on their own learning. }\end{array}$ \\
\hline \multirow[t]{2}{*}{ Opportunity } & \multirow[t]{2}{*}{3} & $\begin{array}{l}\text { Securing learning } \\
\text { opportunities }\end{array}$ & 3 & $\begin{array}{l}\text { By teaching online, students have the opportunity to } \\
\text { learn without restrictions of time and place. }\end{array}$ \\
\hline & & Total & 53 & \\
\hline
\end{tabular}

by comparing it with their own work. For example, the video was used to compare the example given by the work instructor and the students' work behavior. The video can also be used to examine the improvement or growth of the student by comparing the behavior before and after the work training.

\section{Inhibiting Environmental Stimuli}

The use of online meeting apps like Zoom allows the class to be taught in the individual's home or room, reducing the amount of potential environmental stimuli around the individual. For example, by using online Zoom meetings, we were able to confirm reports that students were able to pay more attention to questions and instructions.

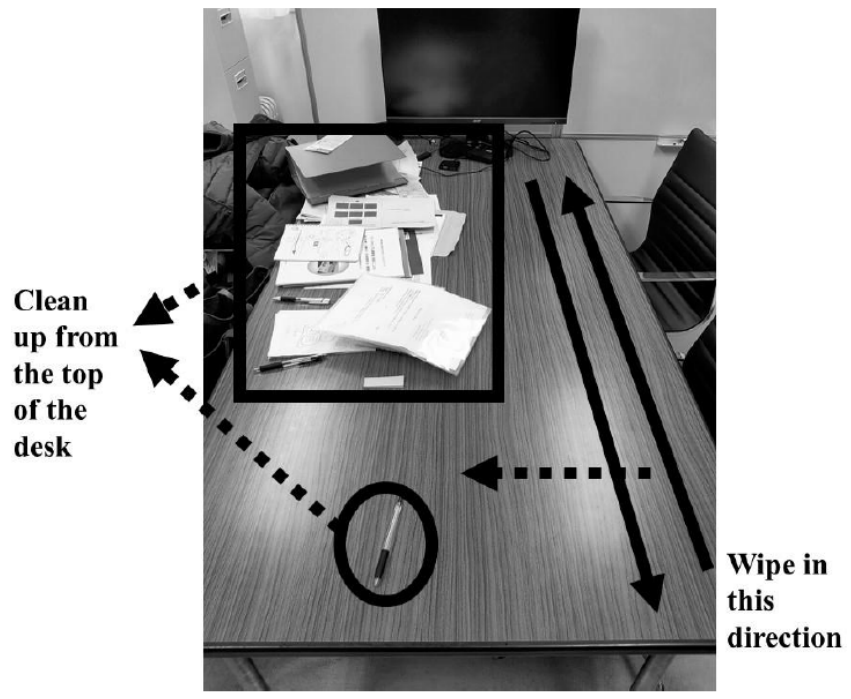

Figure 1: Example of highlighting the cautions of the tasks. 


\section{Category: Support Perspective "Communication"}

In this, the teacher used ICT to help students with intellectual disabilities communicate with their classmates. Regarding the subcategory, the teacher used ICT to help promote the understanding of intellectual disabilities, such as "interaction" and "sharing with others." Based on this perspective of support, these subcategories were grouped as categories of communication. The details of each subcategory are as follows:

\section{Interaction}

The use of online meetings in the classroom provided more opportunities for students to get advice from out-of-school experts and graduates. For example, students were able to receive lectures on their area of interest from distant out-of-school experts and interact with students from other schools. In these interactions, they were able to introduce each other to their career paths after graduation and what they are currently doing.

\section{Sharing with Others}

This use of ICT also empowered the students to communicate their ideas and findings with other students using presentation apps and other software. For example, one student was encouraged to present what they had learned to other students and share the results of their work with others through photos and other means.

\section{Category: Support Perspective "Behavior"}

Teachers used ICT to eliminate behavioral barriers for students with intellectual disabilities. Regarding the subcategory, the teacher used ICT to help promote the understanding of intellectual disabilities, such as "writing" and "supporting positive behavior." Based on this perspective of support, these subcategories were grouped as categories of behavior. The details of each subcategory are as follows:

\section{Writing}

This utilization method involves the use of document creation apps and software on computers and tablets to supplement the behavior of writing, which is a barrier for students. For example, by using apps for note-taking, the barrier of not being able to recall Japanese kanji characters was eliminated, and they could follow the teacher's instructions more easily when writing and revising sentences.

\section{Supporting Positive Behavior}

This method of use allows students to take independent action, such as searching the Internet to obtain information on things that interest them. For example, students could immediately search the Internet for the information they were interested in during the class, or they could be asked to search the Internet for related information before participating in the class to promote a better understanding of what is to be covered in class.

\section{Category: Support Perspective "Meta-Cognition"}

In this, the teacher used ICT to supplement the meta-cognition of students with intellectual disabilities. Regarding the subcategory, the teacher used ICT to help promote understanding of intellectual disabilities, such as "feedback." Based on this perspective of support, these subcategories were grouped as categories of meta-cognition. The details of each subcategory are as follows.

The analysis results indicated that the teachers also used ICT to supplement the meta-cognition of students with intellectual disabilities. This method of support included "feedback".

\section{Feedback}

This method allows students to objectively be aware of their own movements using the recorded video for feedback. For example, a video was recorded during the work activity, which the students viewed after the execution of the movement to obtain feedback on how to improve the teacher's movement or receive feedback from other students.

\section{Category: Support Perspective "Environment"}

In this, the teacher also used ICT to supplement or enhance the environmental arrangements of students with intellectual disabilities.

Regarding the subcategory, the teacher used ICT to help promote the understanding of intellectual disabilities, such as "environmental supplementation." Based on this support perspective, these subcategories were grouped as environment categories. The details of each subcategory are as follows:

\section{Environmental Supplementation}

This method of use is to supplement the environment by using apps to replace the equipment needed for instruction, making the class appear more 
like a real workplace. For example, an app for a cash register was used in sales training, while another app that buzzed students to tell them if they had answered correctly or incorrectly was used.

\section{Category: Support Perspective "Memory"}

In this, the teacher used ICT to supplement students' memory with intellectual disabilities. Regarding the subcategory, the teacher used ICT to help promote understanding of intellectual disabilities, such as "history reference." Based on this perspective of support, these subcategories were grouped as categories of memory. The details of each subcategory are as follows:

\section{History Reference}

This method of use allows students to accumulate data on what they have learned on their own and reflect on their learning by referring to the accumulated data. For example, the system supports the registration of locations and information on local social resources in Google Maps and the storage of learning information in the form of photos and video data.

\section{Category: Support Perspective "Opportunity"}

In this category, the teacher used ICT to supplement learning opportunities for students with intellectual disabilities. Regarding the subcategory, the teacher used ICT to help promote understanding of intellectual disabilities, such as "securing learning opportunities." Based on this perspective of support, these subcategories were grouped as opportunity categories. The details of each subcategory are as follows:

\section{Securing Learning Opportunities}

This utilization method is to provide online classes that can offer students the chance to learn without restrictions on time and place. For example, online classes were offered to help students who could not attend school for various reasons.

\section{DISCUSSION}

This study aimed to clarify the functions of ICT in educational situations for students with intellectual disabilities. The results showed that teachers involved in special needs education for intellectual disabilities used ICT in seven aspects: understanding, communication, behavior, meta-cognition, environment, memory, and opportunities. It was believed that teachers intended to eliminate barriers related to the intellectual disability's comprehension and memory difficulties and the resulting communication, learning, and environmental constraints through ICT-based support such as these.

This study confirms the similarities with the content of assistive technologies in the literature review.

Devi and Sarkar conducted a literature review on assistive technology for people with intellectual disabilities in educational settings. They organized the assistive technologies from their own literature review into eight categories: mobility, positioning/separating, reading, writing, mathematics, communication, recreation, and assessment and evaluation [18]. These eight technologies were confirmed to have much in common with the contents of the subcategories of the seven aspects obtained in this study. Thus, we believe that this study can better collect information on ICT use for persons with intellectual disabilities.

This study shows that teachers have effectively grasped the features of ICT and used them to educate mentally disabled people effectively. Thus, it is an effective tool to compensate for intellectual disabilities as well as to learn better. It is hoped that teachers involved in special needs education can better understand the functions revealed in this study and incorporate them effectively in their education. Alper and Raharinirina have also pointed out the necessity of assessing the matching of students' needs and assistive technologies [19]. For the introduction of ICT in special needs education in Japan, it is necessary for teachers to be able to conduct assessments that can successfully match the needs of individual students with the functions of ICT that were partially revealed in this study, rather than using ICT devices without a clear purpose in the classroom.

In addition, the results do not apply only to educational situations, but they also provide a valid perspective in supporting persons with intellectual disabilities in a work environment. In the special needs schools where students are trained for employment in general companies through practical training, they are assisted by the employees of the general companies as well as their own teachers in their training. In vocational education in Japanese schools, ICT is effectively used as a method to help students understand and acquire specific work skills. The essence of employment support in this training is teaching. For example, it is important for job coaches 
involved in employment assistance to "teach in a way that is easy to understand" [20]. The results of this study indicate a common philosophy between work support and "teaching." Therefore, the results of this study may be used not only for education but also for work support. A literature review of assistive technology for people with intellectual disabilities in the workplace has also shown that assistive technology can improve performance in terms of workplace productivity, guidance, time management, and task execution [21]. Based on the premise that assistive technology has this type of effect, it is necessary to update the technology used to provide work support for persons with intellectual disabilities.

Particularly in Japan, welfare workers seem reluctant to use ICT in support of the disabled. Jyonishi and reported that although workers in welfare facilities feel the need to use ICT devices, they do not think they will actively use ICT due to a lack of knowledge about effective applications for support and their prevention of problems with other persons with disabilities before they occur. While Yamaguchi et al. have reported that many workers in vocational rehabilitation do recognize the difficulty of online work support for persons with intellectual disabilities [23], their reluctance to use ICT in work support is remarkable given how their efficacy has been clearly pointed out before [24]. The results of this study will help consider future support for persons with intellectual disabilities after the coronavirus pandemic, including vocational training, work support, and telework support.

\section{LIMITATIONS}

This was a rare study in Japan since vocational education using ICT is still not sufficiently available.

It is necessary to make efforts to increase the credibility of the results by further increasing the number of survey targets.

In addition, considering the possibility of using the results for future work support, it is necessary to conduct research with other professionals supporting people with intellectual disabilities as research participants.

\section{CONCLUSION}

In recent years, the development of ICT devices has been remarkable. These devices can be an effective tool for persons with intellectual disabilities to facilitate their participation in society and empower them to work independently. This is especially pertinent during the coronavirus pandemic, where close quarters must be avoided, and people should be educated and supported remotely. However, teachers involved with students with intellectual disabilities are currently struggling to cope with the situation. The perspectives revealed in this study are expected to provide such teachers and supporters with helpful perspectives to engage more easily in ICT-based practices. It is hoped that ICT-based education and support can be used to improve support and education for people with intellectual disabilities.

This is a rare study to the best of our knowledge because vocational education using ICT is still not sufficiently available.

We recommend increasing the number of survey targets for better results credibility.

Moreover, it will be better to consider using the results for future work support. It is obligatory to research with other professionals who support intellectually disabled people as research participants.

\section{FUNDING}

This work was supported by the Ministry of Health, Labour, and Welfare of Japan under Grant number $21 \mathrm{GC} 1801$.

\section{CONFLICT OF INTEREST}

No potential conflict of interest was reported by the authors.

\section{ACKNOWLEDGEMENT}

We greatly appreciate the five teachers who participated in this study.

\section{REFERENCES}

[1] American Association on Intellectual Development Disabilities (AAIDD). Intellectual disabilities: Definition, classification, and systems of support. $11^{\text {th }}$ ed. American Association on Intellectual Development Disabilities (AAIDD) 2009.

[2] Abbott S, Mcconkey R. The barriers to social inclusion as perceived by people with intellectual disabilities. J Intellect Disabil 2006; 10(3): 275-87. https://doi.org/10.1177/1744629506067618

[3] Lippold T, Burns J. Social support and intellectual disabilities: a comparison between social networks of adults with intellectual disability and those with physical disability. J Intellect Disabil 2009; 53(5): 463-73.

https://doi.org/10.1111/j.1365-2788.2009.01170.x 
[4] Patterson I, Pegg S. Serious leisure and people with intellectual disabilities: benefits and opportunities. Leisure Studies 2009; 28(4): 387-402. https://doi.org/10.1080/02614360903071688

Martorell A, Gutierrez-Recacha P, Pereda A, Ayuso-Mateos $\mathrm{JL}$. Identification of personal factors that determine work outcome for adults with intellectual disability. J Intellect Disabil 2008; 52(12): 1091-101. https://doi.org/10.1111/j.1365-2788.2008.01098.x

[6] Nota L, Ferrari L, Soresi S, Wehmeyer M. Self-determination, social abilities and the quality of life of people with intellectual disability. J Intellect Disabil 2007; 51(11): 850-65. https://doi.org/10.1111/j.1365-2788.2006.00939.x

[7] Kagohara DM, Meer L, Ramdoss S, et al. Using iPods ${ }^{\circledR}$ and iPads $^{\circledR}$ in teaching programs for individuals with developmental disabilities: A systematic review. Res Dev Disabil 2013; 34(1): 147-56. https://doi.org/10.1016/j.ridd.2012.07.027

[8] Ministry of Education, Culture, Sports, Science and Technology. Realizing the GIGA school initiative [In Japanese]. 2021 Oct 29; [cited: 23 November 2021]. Available from: https://www.mext.go.jp/a_menu/other/index_ 00001.htm

[9] National Association of principals of special needs schools for the education of intellectual disabilities, Eds. Teaching with ICT in special needs schools for the students with intellectual disabilities [In Japanese]. Tokyo: The earth kyoiku-shin-sya 2016.

[10] Mizuuchi T, Aoyama M, Yamanishi J. Effects of using ICT for students with intellectual disabilities: Practical study in the case of standing long jump at the P.E. class [In Japanese]. Educl Inform Res 2018; 33(3): 15-20.

[11] Yamazaki T, Mizuuchi T, Yamanishi J. Practical study for teaching "National Language" subjects to children with intellectual disabilities by using ICT devices and applications [In Japanese]. Toyama Hattatsu Fukushigaku Nempou 2019; 10: $57-61$.

[12] Sawada T. Effective teaching using tablet devices: As a tool for daily support equipment in special support schools for the intellectual disabilities [In Japanese]. Annals of the Graduate School of Teacher Education, Teikyo University 2019; 10: 41-7. http://hdl.handle.net/10682/4312

[13] Taki H, Hioki K, Furuta H. Practice of English education at high school section of special needs education school for students with intellectual disabilities: Utilizing participation of foreign students and Information Communication Technology (ICT) [In Japanese]. Bulletin of Center for Educational Research and School Development Faculty of Education Kumamoto University 2021; 38: 1-8. http://hdl.handle.net/2298/00043668
[14] Fujiwara S, Kurata S, Goto M, Takigawa J. Trial instruction in Music-making/Creation at special schools for children with intellectual disabilities: Focusing on ICT applications [In Japanese]. Bulletin of Center for Educational Research and School Development Faculty of Education Kumamoto University 2021; $\quad 38$ : 115-22. http://hdl.handle.net/2298/00043682

[15] Takatsu A, Okuda K, Tagami K, Tanaka S, Ikuta S. Using Information and Communication Technology to promote the expression of feelings and increase the vocabulary of a student with intellectual disabilities attending a special needs school [In Japanese]. Jpn J Spec Educ 2021; 58(4): 283-92. https://doi.org/10.6033/tokkyou.58.283

[16] Eda Y. Consciousness of teachers on the ICT use for children with disabilities: Based on the results of online training by the video conferencing system [In Japanese] Bulletin of the Faculty of Education, Wakayama University. Educ Sci 2021; 71: 111-8

[17] Kyngäs $H$, Mikkonen K, Kääräinen $M$. The application of content analysis in nursing science research. Springer 2020. https://doi.org/10.1007/978-3-030-30199-6

[18] Devi CR, Sarkar R. Assistive technology for educating persons with intellectual disability. Eur J Spec Educ Res 2019; 4(3): 184-99. http://dx.doi.org/10.46827/ejse.v0i0.2487

[19] Alper S, Raharinirina S. Assistive technology for individuals with disabilities: A review and synthesis of the literature. J Spec Educ Technol 2006; 21(2): 47-64. https://doi.org/10.1177/016264340602100204

[20] Gold MW. Try another way training manual. Illinois: Research Press 1980

[21] Morash-Macneil V, Johnson F, Ryan JB. A systematic review of assistive technology for individuals with intellectual disability in the workplace. J Spec Educ Technol 2017; 33(1): $15-26$.

https://doi.org/10.1177/0162643417729166

[22] Jonishi K, Mochizuki T. Difficulties associated with the use of ICT by persons with disabilities: Analysis of free descriptions in a national survey of type B continuous employment support facilities [In Japanese]. Annual Report of Researches on Development of Welfare Society 2020; 12: 51-60.

[23] Ymaguchi A, Oka K, Maebara K, Nozaki T, Yaeda J. A survey report on the effects of COVID-19 among members of the JSVR [In Japanese]. Jap J Vocat Rehabil 2021; 35(1): 22-9.

[24] Seino K, Maruyama A. The actual status and potential of ICT utilization by providers of continuous employment support Btype services: Comparison of disability types: psychiatric disability, intellectual disability, and physical disability [In Japanese]. Annual Report of Researches on Development of Welfare Society 2020; $12: 35-50$.

\section{https://doi.org/10.6000/2292-2598.2022.10.01.2}

(c) 2022 Maebara et al.; Licensee Lifescience Global.

This is an open access article licensed under the terms of the Creative Commons Attribution License (http://creativecommons.org/licenses/by/4.0/) which permits unrestricted use, distribution and reproduction in any medium, provided the work is properly cited. 